\title{
Correction: Introducing the PLOS special collection of economic cases for NCD prevention and control: A global perspective
}

\section{Rachel A. Nugent, Muhammad Jami Husain, Deliana Kostova, Frank Chaloupka}

There are errors in the Funding statement. The correct Funding statement is as follows: This Collection was supported by TEPHINET, a program of The Task Force for Global Health, Inc., via Cooperative Agreement number NU2GGH001873, funded by the Centers for Disease Control and Prevention. Its contents are solely the responsibility of the authors and do not necessarily represent the official views of the Centers for Disease Control and Prevention, the U.S. Department of Health and Human Services, The Task Force for Global Health, Inc., or TEPHINET.

\section{Reference}

1. Nugent RA, Husain MJ, Kostova D, Chaloupka F (2020) Introducing the PLOS special collection of economic cases for NCD prevention and control: A global perspective. PLoS ONE 15(2): e0228564. https://doi.org/10.1371/journal.pone.0228564 PMID: 32027710

\section{G openaccess}

Citation: Nugent RA, Husain MJ, Kostova D, Chaloupka F (2020) Correction: Introducing the PLOS special collection of economic cases for NCD prevention and control: A global perspective. PLOS ONE 15(5): e0233141. https://doi.org/10.1371/ journal.pone.0233141

Published: May 7, 2020

Copyright: ๑ 2020 Nugent et al. This is an open access article distributed under the terms of the Creative Commons Attribution License, which permits unrestricted use, distribution, and reproduction in any medium, provided the original author and source are credited. 